\title{
Replication of Genetic Associations in the Inflammation, Complement, and Coagulation Pathways With Intraventricular Hemorrhage in LBW Preterm Neonates
}

\author{
KELLI K. RYCKMAN, JOHN M. DAGLE, KEEGAN KELSEY, ALLISON M. MOMANY, AND JEFFREY C. MURRAY
}

Department of Pediatrics [K.K.R., J.M.D., K.K., A.M.M., J.C.M.], Carver College of Medicine, University of Iowa, Iowa City, Iowa 52242; Department of Molecular Biology and Genetics [K.K.], Cornell University, Ithaca, New York 14853

\begin{abstract}
Intraventricular hemorrhage (IVH) is a significant morbidity seen in very LBW infants. Genes related to the inflammation, infection, complement, or coagulation pathways have been implicated as risk factors for IVH. We examined 10 candidate genes for associations with IVH in 271 preterm infants (64 with IVH grades I-IV and 207 without IVH) weighing $<1500$ g. The heterozygous genotype $\mathrm{OR}=8.1, \mathrm{CI}=2.5-26.0, p=4 \times 10^{-4}$ ) and the A allele $\left(\mathrm{OR}=7.3, \mathrm{CI}=2.4-22.5, p=1 \times 10^{-4}\right)$ of the coagulation factor $\mathrm{V}(F V)$ Leiden mutation (rs6025) were associated with an increased risk of developing IVH grade I or II but not grade III or IV after correction for multiple testing with Bonferroni. Lack of association in the severe grades of IVH may be a result of lack of power to detect an effect given the small sample size $(n=8)$. However, this result is consistent with previous research that demonstrates that the heterozygous genotype of the $F V$ mutation is associated with increased risk for the development of IVH but a decreased risk for the progression or extension to more severe grades of IVH. (Pediatr Res 70: 90-95, 2011)
\end{abstract}

$I^{\mathrm{n}}$ ntraventricular hemorrhage (IVH), characterized as bleeding into the ventricular system of the developing brain, is one of the leading morbidities for very LBW (VLBW) preterm neonates $(1,2)$. IVH ranges in severity from grade I to the most severe grade IV. The incidence for IVH grades I-IV is around $27 \%$ in neonates weighing $<1500 \mathrm{~g}$ (1). Approximately, $45-85 \%$ of premature infants with the more severe grades of IVH (grades III-IV) incur cognitive disabilities such as CP and mental retardation, whereas infants with milder grades of IVH (grades I-II) are at risk for developmental delays $(3,4)$. Risk factors for IVH include LBW, early GA, male gender, maternal smoking, preterm premature rupture of membranes (PPROM), chorioamnionitis, early onset sepsis, RDS, patent ductus arteriosus (PDA), and pneumothorax (2,5-8). However, many of these have not been consistently shown as risk factors for IVH and they do not entirely explain the etiology and pathogenesis of this complex disorder (9).

Recently, genetic factors have been implicated in the risk for developing IVH in both term and preterm infants (10-15). Twin studies suggest that shared genetic and environmental

Received October 18, 2010; accepted January 26, 2011.

Correspondence: Jeffrey C. Murray, M.D., Department of Pediatrics, University of Iowa, 500 Newton Road, 2182ML, Iowa City, IA 52242; e-mail: jeff-murray @uiowa.edu Supported by the March of Dimes (grants 1-FY05-126 and 6-FY08-260) and the NIH (grants R01 HD-52953 and R01 HD-57192). Dr. Ryckman's postdoctoral fellowship was supported by a NIH/NRSA T-32 training grant (5T32 HL 007638-24). risk factors explain $41.3 \%$ of the risk for developing IVH after controlling for gender, GA, and birth weight (16). Previous studies of genetic association with IVH have focused on genes related to either inflammation and infection or complement and coagulation. IL1 $\beta-511 \mathrm{~T}$ (rs16944), IL4-590T (rs2243250), IL6-174C (rs1800795), and TNF- $\alpha-308$ (rs1800629) all associated with IVH $(10,17,18)$. In addition, IL10-1082A ( $\mathrm{rs} 1800896)$ is associated with an increased risk of periventricular leukomalacia (PVL), a condition that often occurs in conjunction with IVH $(19,20)$. The coagulation factor $\mathrm{V}(F V)$ Leiden mutation (rs6025), a coagulation factor II (FII), prothrombin polymorphism (G20210A, rs1799963), and a coagulation factor XIII (FXIII) missense mutation (Val34Leu, rs5985) have been implicated in several studies as risk factors for the development of IVH $(12,14,15,21,22)$. In addition, two genes integrin beta-3 (ITGB3) and estrogen receptor-alpha $(E S R 1)$ have been associated with $\operatorname{IVH}(13,23)$. However, many of these associations have not been tested in multiple independent populations or have not consistently replicated across studies.

To determine whether genetic associations previously identified replicate, we examined 10 candidate genes for association with IVH susceptibility: IL1 $\beta, I L A, I L 6, I L 10, T N F, F I I$, $F V, I T G B 3$, and ESR1. We chose either the same single nucleotide polymorphism (SNP) previously associated with IVH or a SNP in high linkage disequilibrium (LD) with the associated SNP and tested associations in 271 preterm infants weighing $<1500 \mathrm{~g}$.

\section{MATERIALS AND METHODS}

Study population. Premature infants (delivery before $37 \mathrm{wk}$ of gestation) admitted to the NICU at the University of Iowa Children's Hospital between 2000 and 2009 were recruited to examine preterm birth (PTB) and neonatal complications of prematurity. Blood or buccal swabs from infants and their parents have been collected and banked. Informed consent was obtained from participating families, and the study was approved by the University of Iowa Institutional Review Board (200506792) for sample recruitment and to access

Abbreviations: APGAR, appearance, pulse, grimace, activity, respiration; c-PVL, cystic periventricular leukomalacia; ESR1, estrogen receptor-alpha; FII, coagulation factor II; FV, coagulation factor V; HWE, Hardy-Weinberg equilibrium; ITGB3, integrin beta-3; IVH, intraventricular hemorrhage; LD, linkage disequilibrium; PDA, patent ductus arteriosus; PPROM, preterm premature rupture of membranes; PVL, periventricular leukomalacia; SNP, single nucleotide polymorphism; VLBW, very LBW 
the associated clinical information necessary for this study. This population is a subset of one that has been described previously but evaluated for PTB with respect to the progesterone receptor and genes affecting cholesterol metabolism $(24,25)$.

The first analysis consisted of 271 unrelated infants born $<32$ wk of gestation and weighing $<1500 \mathrm{~g}$. There were 48 sets of twins in this study, one twin was chosen from each pair. The twin with the most severe case of IVH was selected, if both twins had the same IVH status one twin was randomly selected. Cases were defined as infants with IVH grades I-IV, and controls were those without documented IVH. IVH grade was confirmed by ultrasonography with grade I defined as blood in the periventricular germinal matrix, grade II as blood in the ventricular system without ventricular dilatation, grade III as blood in the lateral ventricles with ventricular dilatation, and grade IV as blood in the ventricular system with parenchymal extension. We studied 207 infants without IVH, 28 with grade I, 10 with grade II, 16 with grade III, and 10 with grade IV. Demographics of this population are described in Table 1. A second phase of the study was performed after removing confounders that could potentially interfere with inflammation/ infection and coagulation genetic associations. Exclusions included infants of women with heart disease $(0.37 \%)$, bleeding disorder $(1.1 \%)$, autoimmune disease $(0.0 \%)$, thrombocytopenia $(2.2 \%)$, gestational diabetes $(3.0 \%)$, type I diabetes $(0.74 \%)$, type II diabetes $(1.1 \%)$, chronic hypertension $(8.9 \%)$, preeclampsia $(28.0 \%)$, eclampsia $(1.1 \%)$, gestational hypertension $(5.5 \%)$, hemolysis, elevated liver enzymes and low platelet count (HELLP) syndrome (7.7\%), infants with congenital anomalies (3.0\%), infants who were a twin $(17.7 \%)$, and infants with one or both parents of non-Caucasian descent $(23.2 \%)$. Race of infant was determined through self-reported questionnaire of the mother. The remaining subset included 103 infants, 81 without IVH, 10 with grade I, 4 with grade II, 8 with grade III, and none with grade IV.

DNA processing and genotyping. DNA was extracted from blood or buccal swabs (26). Ten SNPs were chosen for analysis with IVH; seven have been shown to associate with IVH previously (IL10-1082 rs1800896, TNF308 rs1800629, FII G20210A rs1799963, FV G1691A rs6025, FXIII Val34Leu rs5985, ITGB3 Leu33Pro rs5918, ESR1 rs2234693) and three were in strong LD with SNPs previously reported to be associated with IVH (IL1 $\beta$-31 rs1143627 with IL1 $\beta$-511 rs16944 $r^{2}=0.96$; IL6 rs2069832 with IL6-174 rs1800795, $r^{2}=0.96$; and ILA rs2243270 with IL4-590 rs2243250, $\left.r^{2}=0.94\right)$. LD was determined using the Caucasian population (CEU) from
Hapmap. Genotyping was performed using TaqMan (Applied Biosystems, Foster City, CA), as previously described (24). Allele scoring was done using the Sequence Detection Systems software (version 2.2, Applied Biosystems). The genotype data were uploaded into a Progeny database (Progeny Software, LLC, South Bend, IN), also containing phenotypic data, for subsequent statistical analysis.

Statistical analysis. Demographic characteristics were compared between infants without IVH $(n=207)$ and infants with IVH grades I-IV $(n=64)$ using the Wilcoxon rank sum test when comparing continuous traits and Fisher's exact test for dichotomous traits. The first dataset included 271 infants born $<32$ wk of gestation and weighing $<1500 \mathrm{~g}$. The second set included 103 infants after excluding the potential confounders described above. Markers were tested for deviations from Hardy-Weinberg Equilibrium (HWE) with Fisher's exact tests. Fisher's exact tests were also used to compare genotype and allele frequencies between the following groups; 1) infants without IVH and those with IVH grades I-IV; 2) infants without IVH and those with IVH grades I-II, and 3) infants without IVH and those with IVH grades III-IV. A Bonferroni significance level of $p<5 \times 10^{-3}(0.05 / 10$ independent tests) was used to correct for multiple testing. Logistic regression was performed on SNPs with significant $(p<0.05)$ genotype differences. The OR and CI using the Woolf test was calculated for SNPs with significant $(p<$ $0.05)$ allele frequency differences. Statistical analysis was performed in Stata version 10.1 (Stata Corp, College Station, TX). In addition, logistic regression was performed after controlling for factors that differed by IVH status (Table 1), specifically appearance, pulse, grimace, activity, respiration (Apgar score) at 1 and 5 min, cystic PVL (c-PVL), twin status, and PDA. Power analysis was performed with PS Power (27).

\section{RESULTS}

Demographic data. Birth weight, GA, race, gender, retinopathy of prematurity (ROP), RDS, necrotizing entercolitis, (NEC), sepsis, pneumothorax, smoking during pregnancy, diabetes, hypertension, PPROM, maternal preexisting conditions, thrombocytopenia, and congenital anomalies did not differ between infants with IVH compared to those without

Table 1. Demographic characteristics of 271 unrelated infants with $(\mathrm{n}=64)$ and without $(\mathrm{n}=207)$ IVH

\begin{tabular}{|c|c|c|c|}
\hline Trait & No IVH $(n=207)$ & IVH $(n=64)$ & $p^{*}$ \\
\hline Birth weight $(n=271)$ & $948(416)$ & $1,026(485)$ & 0.38 \\
\hline $\mathrm{GA}(n=271)$ & $28(3)$ & $27(4)$ & 0.34 \\
\hline APGAR $1 \min (n=268)$ & $6(3)$ & $4(4)$ & $1.0 \times 10^{-4}$ \\
\hline APGAR $5 \min (n=269)$ & $8(2)$ & $6(3)$ & $2.0 \times 10^{-4}$ \\
\hline Race $(n=270)$ & & & 0.31 \\
\hline African-American & $25(12.1 \%)$ & $7(10.9 \%)$ & \\
\hline Hispanic & $12(5.8 \%)$ & $6(9.4 \%)$ & \\
\hline Caucasian & $162(78.6 \%)$ & $46(71.9 \%)$ & \\
\hline Other & $7(3.4 \%)$ & $5(7.8 \%)$ & \\
\hline Infant is a twin $(n=271)$ & $28(13.5 \%)$ & $20(31.3 \%)$ & $2.0 \times 10^{-3}$ \\
\hline Gender-male $(n=271)$ & $120(58.0 \%)$ & $38(59.4 \%)$ & 0.89 \\
\hline $\operatorname{PVL}(n=271)$ & $5(2.4 \%)$ & $11(17.2 \%)$ & $9.7 \times 10^{-5}$ \\
\hline $\operatorname{ROP}(n=262)$ & $66(32.5 \%)$ & $24(40.7 \%)$ & 0.28 \\
\hline $\operatorname{PDA}(n=271)$ & $74(35.8 \%)$ & $34(53.1 \%)$ & 0.02 \\
\hline $\operatorname{RDS}(\mathrm{n}=271)$ & $174(84.1 \%)$ & $55(85.9 \%)$ & 0.84 \\
\hline $\operatorname{NEC}(n=271)$ & $17(8.2 \%)$ & $2(3.1 \%)$ & 0.26 \\
\hline Sepsis $(n=115)$ & $62(70.5 \%)$ & $19(70.4 \%)$ & 1.00 \\
\hline Pneumothorax $(n=270)$ & $12(5.8 \%)$ & $4(6.3 \%)$ & 1.00 \\
\hline Smoked during pregnancy $(n=257)$ & $44(22.0 \%)$ & $46(22.8 \%)$ & 0.86 \\
\hline $\operatorname{PPROM}(n=271)$ & $40(19.3 \%)$ & $13(20.3 \%)$ & 0.86 \\
\hline Diabetes $(n=271)$ & $10(4.8 \%)$ & $3(4.7 \%)$ & 1.00 \\
\hline Clinical chorioamnionitis $(n=219)$ & $27(15.7 \%)$ & $6(12.8 \%)$ & 0.82 \\
\hline Hypertension/preeclampsia/eclampsia $(n=271)$ & $75(36.2 \%)$ & $15(23.4 \%)$ & 0.07 \\
\hline Heart disease/bleeding disorder/autoimmune disease $(n=65)$ & $3(6.3 \%)$ & $1(5.9 \%)$ & 1.00 \\
\hline Thrombocytopenia $(n=31)$ & $3(12.5 \%)$ & $3(42.8 \%)$ & 0.11 \\
\hline Congenital anomaly $(n=271)$ & $7(3.4 \%)$ & $1(1.6 \%)$ & 0.69 \\
\hline
\end{tabular}

Median and interquartile range is given for continuous traits, and counts and percentages are given for dichotomous traits. Numbers of nonmissing observations are given for each trait.

* $p$ values were calculated with Wilcoxon rank sum test for continuous traits and Fisher's exact test for dichotomous traits.

ROP, retinopathy of prematurity; NEC, necrotizing enterocolitis. 
IVH (Table 1). As expected c-PVL was more frequent in infants with IVH (17.2\%) compared to those without IVH $\left(2.4 \% ; p=9.7 \times 10^{-5}\right)$. This association has been documented in previous reports (10). PDA was also more common in infants with IVH $(53.1 \%)$ compared to those without IVH (35.8\%; $p=0.02)$. In addition, as expected infants with IVH had lower Apgar scores at 1 and 5 min compared to those without IVH. There was also a higher incidence of twins among infants with IVH (31.3\%) compared to those without $(13.5 \%)$.

Genetic associations with IVH. All markers were in HWE in infants with and without IVH in the full dataset $(n=271)$. In the dataset after exclusion of potential confounders all the markers were in HWE with the exception of ESRI rs2234693 $(p=0.03)$ in infants with IVH. When comparing infants with and without IVH, we detected allele and genotype frequency differences for $I L 1 \beta$ rs 1143627 and $F V$ rs6025 in both the full dataset and the dataset with exclusions (Table 2). Infants with the $\mathrm{CC}$ genotype $(\mathrm{OR}=3.1, \mathrm{CI}=1.3-7.5, p=0.01)$, the $\mathrm{CT}$ genotype $(\mathrm{OR}=2.2, \mathrm{CI}=1.1-4.7, p=0.04)$, or the $\mathrm{C}$ allele $\left(\mathrm{OR}=1.8, \mathrm{CI}=1.2-2.8, p=5 \times 10^{-3}\right)$ of $I L 1 \beta \mathrm{rs} 1143627$ were at increased risk for IVH compared to infants with the TT genotype or T allele. After excluding infants with potential confounders the association with IVH and the CT genotype of $I L 1 \beta$ rs1143627 remained $(\mathrm{OR}=4.2, \mathrm{CI}=1.2-14.6, p=$ $0.03)$; however, the associations with the CC genotype ( $p=$ $0.56)$ and the $C$ allele $(p=0.23)$ were no longer significant, possibly because of the decreased sample size and lack of power to detect the effects (Table 2). After controlling for factors that significantly differed by IVH in Table 1 ; i.e. Apgar scores at 1 and $5 \mathrm{~min}, \mathrm{c}-\mathrm{PVL}$, twin status, and PDA, the CT $(\mathrm{OR}=2.8, \mathrm{CI}=1.2-6.8, p=0.02)$ and $\mathrm{CC}(\mathrm{OR}=3.7, \mathrm{CI}=$ $1.3-10.2, p=0.02)$ genotypes were associated with increased risk for IVH in the full data and the $\mathrm{CT}$ genotype only $(\mathrm{OR}=$ $4.0, \mathrm{CI}=1.1-14.8, p=0.04$ ) was associated with increased risk for IVH in the data after exclusion criteria.

Infants heterozygous $(\mathrm{OR}=4.9, \mathrm{CI}=1.6-14.8, p=5 \times$ $\left.10^{-3}\right)$ or with the A allele $(\mathrm{OR}=4.6, \mathrm{CI}=1.6-13.6, p=2 \times$ $10^{-3}$ ) of the $F V$ Leiden mutation were at increased risk for IVH. After excluding infants with potential confounders, infants heterozygous for the $F V$ Leiden mutation $(\mathrm{OR}=14.4$, $\mathrm{CI}=1.4-147.9, p=0.02)$ or with the A allele $(\mathrm{OR}=13.3$, $\mathrm{CI}=1.3-131.6, p=5 \times 10^{-3}$ ) were at increased risk for IVH. Only the association between $F V$ rs6025 and IVH in the full dataset was significant after correction for multiple testing with Bonferroni. After controlling for Apgar scores at 1 and 5 min, c-PVL, twin status, and PDA, heterozygotes for the $F V$ Leiden mutation were still at increased risk for IVH in the full data $(\mathrm{OR}=4.0, \mathrm{CI}=1.1-14.9, p=0.04)$ and after exclusion criteria $(\mathrm{OR}=17.7,1.3-244.7, p=0.03)$.

Genetic associations with grade of IVH. IL1 $\beta$ rs1143627 was significant or marginally significant for allele and genotype differences when comparing infants without IVH to those with IVH grades I-II or IVH grades III-IV (Table 3). Infants with the CT genotype $(\mathrm{OR}=3.0, \mathrm{CI}=1.1-7.9, p=0.03)$ or the $\mathrm{C}$ allele $(\mathrm{OR}=1.7, \mathrm{CI}=0.99-3.0, p=0.05)$ of $I L 1 \beta$

Table 2. Genetic associations comparing premature infants $(<32$ wk gestation and $<1500 \mathrm{~g})$ with and without IVH

\begin{tabular}{|c|c|c|c|c|c|c|c|c|c|c|c|}
\hline \multicolumn{2}{|c|}{$\begin{array}{l}\text { Full data } \\
(n=271)\end{array}$} & \multicolumn{4}{|c|}{$\begin{array}{l}\text { No IVH } \\
(n=207)\end{array}$} & \multicolumn{4}{|c|}{$\begin{array}{c}\text { IVH } \\
(n=64)\end{array}$} & \multicolumn{2}{|c|}{$p^{*}$ No IVH $v s$ IVH } \\
\hline Gene & rs\# (A/B) & AA & $\mathrm{AB}$ & $\mathrm{BB}$ & F_A $†$ & AA & $\mathrm{AB}$ & $\mathrm{BB}$ & $\mathrm{F} \_\mathrm{A} \dagger$ & Genotype & Allele \\
\hline$I L 1 \beta$ & rs1143627 (C/T) & 30 & 81 & 80 & 0.37 & 14 & 27 & 12 & 0.52 & 0.02 & $7.0 \times 10^{-3}$ \\
\hline IL6 & rs2069832 (A/G) & 18 & 70 & 81 & 0.31 & 6 & 21 & 23 & 0.33 & 0.92 & 0.81 \\
\hline IL4 & rs2243270 (A/G) & 94 & 52 & 10 & 0.77 & 31 & 11 & 2 & 0.83 & 0.50 & 0.25 \\
\hline ILIO & rs1800896 (A/G) & 54 & 103 & 42 & 0.53 & 16 & 35 & 11 & 0.54 & 0.79 & 0.92 \\
\hline$T N F$ & rs1800629 (A/G) & 5 & 45 & 142 & 0.14 & 0 & 19 & 39 & 0.16 & 0.23 & 0.66 \\
\hline$F I I$ & rs1799963 (A/G) & 0 & 4 & 176 & 0.01 & 0 & 3 & 53 & 0.03 & 0.36 & 0.36 \\
\hline$F V$ & rs6025 (G/A) & 188 & 6 & 0 & 0.98 & 51 & 8 & 0 & 0.93 & $5.0 \times 10^{-3} \ddagger$ & $6.0 \times 10^{-3}$ \\
\hline$F X I I I$ & Rs5985 (G/T) & 49 & 29 & 5 & 0.77 & 19 & 4 & 1 & 0.88 & 0.18 & 0.11 \\
\hline$I T G B 3$ & rs5918 (C/T) & 4 & 51 & 117 & 0.17 & 0 & 12 & 40 & 0.12 & 0.49 & 0.22 \\
\hline ESR1 & rs2234693 (C/T) & 44 & 93 & 48 & 0.49 & 14 & 26 & 16 & 0.48 & 0.88 & 0.91 \\
\hline \multicolumn{2}{|c|}{$\begin{array}{l}\text { Data with exclusions } \\
\qquad(n=103) \S\end{array}$} & \multicolumn{4}{|c|}{$\begin{array}{l}\text { No IVH } \\
(n=81)\end{array}$} & \multicolumn{4}{|c|}{$\begin{array}{c}\text { IVH } \\
(n=22)\end{array}$} & \multicolumn{2}{|c|}{$p^{*}$ No IVH $v s$ IVH } \\
\hline$I L 1 \beta$ & rs1143627 (C/T) & 11 & 25 & 38 & 0.32 & 2 & 11 & 4 & 0.44 & 0.05 & 0.23 \\
\hline IL6 & rs2069832 (A/G) & 10 & 31 & 24 & 0.39 & 2 & 9 & 7 & 0.36 & 1.00 & 0.85 \\
\hline IL4 & rs2243270 (A/G) & 43 & 21 & 0 & 0.84 & 14 & 3 & 0 & 0.91 & 0.37 & 0.42 \\
\hline ILIO & rs1800896 (A/G) & 20 & 40 & 19 & 0.51 & 2 & 14 & 4 & 0.45 & 0.25 & 0.60 \\
\hline$T N F$ & rs1800629 (A/G) & 2 & 13 & 61 & 0.11 & 0 & 8 & 11 & 0.21 & 0.08 & 0.11 \\
\hline$F I I$ & rs1799963 (A/G) & 0 & 2 & 70 & 0.01 & 0 & 2 & 17 & 0.05 & 0.19 & 0.19 \\
\hline$F V$ & rs6025 (G/A) & 77 & 1 & 0 & 0.99 & 16 & 3 & 0 & 0.92 & 0.02 & 0.02 \\
\hline FXIII & $\operatorname{Rs} 5985$ (G/T) & 20 & 15 & 0 & 0.79 & 6 & 1 & 0 & 0.93 & 0.22 & 0.29 \\
\hline ITGB3 & rs5918 (C/T) & 2 & 25 & 43 & 0.21 & 0 & 8 & 9 & 0.24 & 0.73 & 0.82 \\
\hline ESR1 & rs2234693 (C/T) & 17 & 36 & 20 & 0.48 & 9 & 5 & 6 & 0.58 & 0.08 & 0.37 \\
\hline
\end{tabular}

$* p$ is calculated with Fisher's exact test comparing infants with no documented IVH to those with documented IVH grades I-IV.

$\dagger$ F_A is the allele frequency of the A allele.

\$ Significant after correction for multiple testing with Bonferroni (threshold of $5 \times 10^{-3}$ ).

$\S$ Infants of women with heart disease, bleeding disorder, autoimmune disease, thrombocytopenia, gestational diabetes, type I diabetes, type II diabetes, chronic hypertension, pre-eclampsia, eclampsia, gestational hypertension, HELLP syndrome, infants with congenital anomalies, infants who were a twin or triplet, and infants with one or both parents of non-Caucasian descent were excluded from analysis leaving a sample size of 103 infants. 
Table 3. Genetic associations comparing premature infants $(<32$ weeks gestation and $<1500 \mathrm{~g})$ without IVH to those with grades I-II and those with grades III-IV

\begin{tabular}{|c|c|c|c|c|c|c|c|c|c|c|c|c|c|c|c|c|c|}
\hline \multicolumn{2}{|r|}{$\begin{array}{l}\text { Full data } \\
(n=271)\end{array}$} & \multicolumn{4}{|c|}{$\begin{array}{l}\text { No IVH } \\
(n=207)\end{array}$} & \multicolumn{4}{|c|}{$\begin{array}{l}\text { IVH grades I and II } \\
\qquad(n=38)\end{array}$} & \multicolumn{4}{|c|}{$\begin{array}{l}\text { IVH grades III and IV } \\
\qquad(n=26)\end{array}$} & \multicolumn{2}{|c|}{$\begin{array}{l}p^{*} \text { No IVH } v s \\
\text { grades I and II }\end{array}$} & \multicolumn{2}{|c|}{$\begin{array}{l}p^{*} \text { No IVH } v s \\
\text { grades III and IV }\end{array}$} \\
\hline Gene & rs\# (A/B) & AA & $\mathrm{AB}$ & BB & $\mathrm{F}_{-} \mathrm{A} \dagger$ & AA & $\mathrm{AB}$ & BB & $\mathrm{F}_{-} \mathrm{A} \dagger$ & AA & $\mathrm{AB}$ & BB & $\mathrm{F}_{-} \mathrm{A} \dagger$ & Genotype & Allele & Genotype & Allele \\
\hline$I L 1 \beta$ & rs1143627 (C/T) & 30 & 81 & 80 & 0.37 & 6 & 18 & 6 & 0.50 & 8 & 9 & 6 & 0.54 & 0.06 & 0.06 & 0.07 & 0.03 \\
\hline IL6 & rs2069832 (A/G) & 18 & 70 & 81 & 0.31 & 5 & 9 & 13 & 0.35 & 1 & 12 & 10 & 0.30 & 0.41 & 0.64 & 0.52 & 1.00 \\
\hline IL4 & rs $2243270(\mathrm{~A} / \mathrm{G})$ & 94 & 52 & 10 & 0.77 & 16 & 8 & 0 & 0.83 & 15 & 3 & 2 & 0.83 & 0.62 & 0.36 & 0.17 & 0.55 \\
\hline IL10 & rs1800896 (A/G) & 54 & 103 & 42 & 0.53 & 12 & 18 & 7 & 0.57 & 4 & 17 & 4 & 0.50 & 0.80 & 0.61 & 0.35 & 0.76 \\
\hline$T N F$ & rs1800629 (A/G) & 5 & 45 & 142 & 0.14 & 0 & 10 & 23 & 0.15 & 0 & 9 & 16 & 0.18 & 0.59 & 0.85 & 0.39 & 0.52 \\
\hline$F I I$ & rs1799963 (A/G) & 0 & 4 & 176 & 0.01 & 0 & 1 & 33 & 0.01 & 0 & 2 & 20 & 0.05 & 0.58 & 0.58 & 0.13 & 0.13 \\
\hline$F V$ & rs6025 (G/A) & 188 & 6 & 0 & 0.98 & 27 & 7 & 0 & 0.90 & 24 & 1 & 0 & 0.98 & $1.0 \times 10^{-3} \ddagger$ & $1.0 \times 10^{-3} \ddagger$ & 0.58 & 0.58 \\
\hline FXIII & Rs5985 (G/T) & 49 & 29 & 5 & 0.77 & 10 & 3 & 0 & 0.88 & 9 & 1 & 1 & 0.86 & 0.59 & 0.21 & 0.18 & 0.42 \\
\hline ITGB3 & rs5918 (C/T) & 4 & 51 & 117 & 0.17 & 0 & 7 & 23 & 0.12 & 0 & 5 & 17 & 0.11 & 0.75 & 0.35 & 0.77 & 0.40 \\
\hline ESR1 & rs2234693 (C/T) & 44 & 93 & 48 & 0.49 & 10 & 14 & 9 & 0.52 & 4 & 12 & 7 & 0.43 & 0.65 & 0.79 & 0.77 & 0.53 \\
\hline \multicolumn{2}{|c|}{$\begin{array}{l}\text { Data with exclusions } \\
\qquad(n=103)\end{array}$} & \multicolumn{4}{|c|}{$\begin{array}{l}\text { No IVH } \\
(n=81)\end{array}$} & \multicolumn{4}{|c|}{$\begin{array}{l}\text { IVH grades I and II } \\
\qquad(n=14)\end{array}$} & \multicolumn{4}{|c|}{$\begin{array}{l}\text { IVH grades III } \\
\quad(n=8)\end{array}$} & \multicolumn{2}{|c|}{$\begin{array}{l}p^{*} \text { No IVH } v s \\
\text { grades I and II }\end{array}$} & \multicolumn{2}{|c|}{$\begin{array}{l}p^{*} \text { No IVH } v s \\
\text { grades III }\end{array}$} \\
\hline$I L 1 \beta$ & rs1143627 (C/T) & 11 & 25 & 38 & 0.32 & 1 & 7 & 3 & 0.41 & 1 & 4 & 1 & 0.50 & 0.15 & 0.47 & 0.19 & 0.21 \\
\hline IL6 & rs2069832 (A/G) & 10 & 31 & 24 & 0.39 & 2 & 5 & 4 & 0.41 & 0 & 4 & 3 & 0.29 & 1.00 & 1.00 & 0.75 & 0.57 \\
\hline IL4 & rs2243270 (A/G) & 43 & 21 & 0 & 0.84 & 7 & 3 & 0 & 0.85 & 7 & 0 & 0 & 1.00 & 1.00 & 1.00 & 0.10 & 0.13 \\
\hline IL10 & rs1800896 (A/G) & 20 & 40 & 19 & 0.51 & 2 & 8 & 3 & 0.46 & 0 & 6 & 1 & 0.43 & 0.80 & 0.83 & 0.26 & 0.78 \\
\hline$T N F$ & rs $1800629(\mathrm{~A} / \mathrm{G})$ & 2 & 13 & 61 & 0.11 & 0 & 4 & 7 & 0.18 & 0 & 4 & 4 & 0.25 & 0.41 & 0.31 & 0.11 & 0.12 \\
\hline$F I I$ & rs1799963 (A/G) & 0 & 2 & 70 & 0.01 & 0 & 1 & 12 & 0.04 & 0 & 1 & 5 & 0.08 & 0.40 & 0.39 & 0.22 & 0.22 \\
\hline$F V$ & $\operatorname{rs} 6025(\mathrm{G} / \mathrm{A})$ & 77 & 1 & 0 & 0.99 & 8 & 3 & 0 & 0.86 & 8 & 0 & 0 & 1.00 & $5.0 \times 10^{-3} \ddagger$ & $6.0 \times 10^{-3}$ & 1.00 & 1.00 \\
\hline FXIII & rs5985 (G/T) & 20 & 15 & 0 & 0.79 & 3 & 1 & 0 & 0.88 & 3 & 0 & 0 & 1 & 0.63 & 1.00 & 0.26 & 0.59 \\
\hline ITGB3 & rs5918 (C/T) & 2 & 25 & 43 & 0.21 & 0 & 4 & 6 & 0.20 & 0 & 4 & 3 & 0.29 & 1.00 & 1.00 & 0.52 & 0.50 \\
\hline ESR1 & rs2234693 (C/T) & 17 & 36 & 20 & 0.48 & 6 & 5 & 2 & 0.65 & 3 & 0 & 4 & 0.43 & 0.29 & 0.14 & 0.02 & 0.79 \\
\hline
\end{tabular}

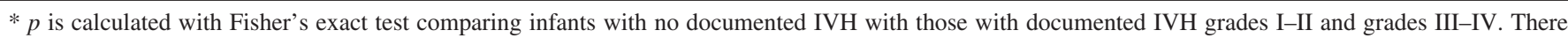
were no infants with grade IV IVH after exclusions, so comparisons are only made with IVH grade III.

$\dagger$ F_A is the allele frequency of the A allele.

\$ Significant after correction for multiple testing with Bonferroni (threshold of $5 \times 10^{-3}$ ).

$\S$ Infants of women with heart disease, bleeding disorder, autoimmune disease, thrombocytopenia, gestational diabetes, type I diabetes, type II diabetes, chronic

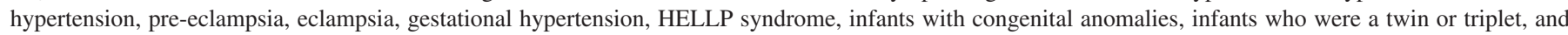
infants with one or both parents of non-Caucasian descent were excluded from analysis leaving a sample size of 103 infants.

rs1143627 were at increased risk for IVH grades I-II compared to infants with the TT genotype or T allele. Infants with the $\mathrm{CC}$ genotype $(\mathrm{OR}=3.6, \mathrm{CI}=1.1-11.1, p=0.03)$ or the $\mathrm{C}$ allele $(\mathrm{OR}=2.0, \mathrm{CI}=1.1-3.8, p=0.02)$ of $I L 1 \beta$ rs1143627 were at increased risk for IVH grades III-IV compared to infants with the TT genotype or T allele. These associations were not significant after correction for multiple testing with Bonferroni nor did they remain significant after excluding infants for potential confounders (Table 3). After controlling for Apgar scores at 1 and $5 \mathrm{~min}$, c-PVL, twin status, and PDA, the CT $(\mathrm{OR}=3.1,1.1-8.8, p=0.03)$ but not CC genotype $(p=0.1)$ increased risk for IVH grades I-II and the $\mathrm{CC}(\mathrm{OR}=6.5,1.3-33.8, p=0.03)$ but not $\mathrm{CT}$ ( $p=$ $0.2)$ genotype increased risk for IVH grades III-IV in the full data. These results did not remain significant $(p>0.05)$ in the data after exclusions.

When comparing infants with grades I-II IVH to those without IVH, there were allele and genotype frequency differences for $F V$ rs6025 in both the full dataset and the dataset with exclusions (Table 3). Associations in both the full dataset and the dataset with exclusions were significant after correction for multiple testing with Bonferroni. Infants heterozygous $\left(\mathrm{OR}=8.1, \mathrm{CI}=2.5-26.0, p=4 \times 10^{-4}\right)$ or with the A allele $\left(\mathrm{OR}=7.3, \mathrm{CI}=2.4-22.5, p=1 \times 10^{-4}\right)$ for the $F V$ Leiden mutation were at increased risk for IVH grades I-II. After excluding infants for potential confounders, the association with IVH and both the heterozygous genotype $(\mathrm{OR}=28.9$, $\left.\mathrm{CI}=2.7-311.2, p=6 \times 10^{-3}\right)$ and the A allele $(\mathrm{OR}=24.5$, $\mathrm{CI}=2.4-247.2, p=1 \times 10^{-4}$ ) remained significant; however, there was no association in either dataset when comparing IVH grades III-IV to infants without IVH $(p>0.5)$. However, the power to detect the same effect in the A allele as observed in IVH grades I-II was $70 \%$ and therefore lack of association cannot be adequately established. After controlling for Apgar scores at 1 and 5 min, c-PVL, twin status, and PDA, heterozygotes for the $F V$ Leiden mutation were still at increased risk for IVH grades I-II in the full data $(\mathrm{OR}=5.5$, $\mathrm{CI}=1.5-20.0, p=0.01)$ and after exclusion criteria $(\mathrm{OR}=$ $40.5,2.0-840.1, p=0.02)$.

\section{DISCUSSION}

Genetic studies of IVH have largely focused on genes involved in inflammation and infection, because this pathway is strongly implicated in the pathophysiology of perinatal brain injury, supported by animal models and studies in human preterm infants (10). We sought to replicate 10 candidate genes from the inflammation/infection and complement/ coagulation pathways for association with IVH. We identified two genes (ILI $\beta$ (rs16944) and $F V$ (rs6025)) that associated with the risk for IVH in our cohort; thereby replicating previous studies. 
Previously, the IL1 $\beta-511$ (rs16944) T allele was associated with an increased risk of IVH in 215 VLBW infants compared to the $\mathrm{C}$ allele $(\mathrm{OR}=3.0, \mathrm{CI}=1.4-6.4, p=0.003)(10)$. We validated this result by finding that the $I L 1 \beta-31$ (rs1143627) C allele was associated with an increased risk of IVH $(p=$ 0.007). This finding was significant or marginally significant for both IVH grades I-II and IVH grades III-IV. The C allele of IL1 $\beta-31$ is in strong LD $\left(r^{2}=0.96\right)$ with the T allele of $I L 1 \beta-511$. The $I L 1 \beta-31 \mathrm{C}$ allele is associated with an increased production of IL1 $\beta$ in vivo (28). There is substantive evidence that IL1 $\beta$ is involved in the pathophysiology of perinatal brain injury. Injection of IL1 $\beta$ causes brain injury in neonatal rats, and increased amniotic and/or cord blood levels of IL1 $\beta$ are observed in infants with PVL and IVH (29-33). The exact mechanisms by which IL1 $\beta$ is involved in IVH and perinatal injury is still not entirely clear; however, our research has identified that the same allele of $I L 1 \beta-31$ (C allele) associated with increased levels of $\operatorname{IL} 1 \beta$ is also associated with an increased risk of IVH.

Coagulation factors, specifically FII, FV, and FXIII have been considered as possible candidate genes for IVH because of likely interactions between thrombophilic factors and the pathology of IVH. It is hypothesized that increased fibrinolytic activity and decreased levels of clotting factors may contribute to the severity of intracranial bleeding that can occur in preterm infants $(34,35)$. We found no significant associations with FII or FXIII; however, the FV Leiden mutation (rs6025) and IVH were strongly associated. The heterozygous genotype of rs6025 was previously shown to associate with an increased risk for IVH and to protect against the extension and/or progression to more severe grades of IVH $(14,22)$. Our study supports these findings as the heterozygous genotype of the $F V$ Leiden mutation was significantly associated in infants with IVH grades I-II $\left(p=5 \times 10^{-3}\right)$ but not IVH grades III-IV $(p=1.0)$. However, the lack of association detected in the severe grades of IVH must be interpreted with caution, because of the small sample size in the more severe grades of IVH $(n=8)$ and therefore lack of power $(70 \%)$ to detect the same effect seen in IVH grades I-II $(\mathrm{OR}=24.5)$. Moreover, it is to be noted that the effect size seen in the IVH grades I-II groups after stringent exclusions is likely inflated because of the small sample size; therefore, the power to detect an effect in the severe IVH group is likely lower. The $F V$ Leiden variant has about a 5\% allele frequency in the Caucasian population and is a glutamine to arginine replacement at amino acid position 506 that results in an increased risk for thrombosis (36). The associations with the $F V$ Leiden mutation were the only results in our study that withstood Bonferroni correction for multiple testing and lends evidence to the hypothesis that the complement coagulation pathway is involved in the risk for the development of IVH.

Although several studies have found associations with the $F V$ Leiden mutation (rs6025) $(10,14,15,21,22)$ there have also been other studies that failed to find association $(10,37)$. This could be due to ethnic heterogeneity, varied study design, or lack of an adequate control group for comparison. A strength of our study was the ability to compare very preterm $(<32 \mathrm{wk}$ of gestation) VLBW $(<1500 \mathrm{~g})$ infants with IVH to very preterm VLBW infants without IVH, whereas other studies have compared infants with IVH to term infants without IVH and their associations are therefore confounded by GA and birth weight. However, one weakness of our study is a relatively small sample size and therefore associations that were not detected in our analysis may not be indicative of lack of association but rather because of the limited power to detect the effects. For example, for the genes for which no allelic association was detected (IL4, IL6, IL10, TNF, FII, FXIII, ITGB3, and ESR1), the power to detect these associations only reached $80 \%$ for effect sizes larger than an OR of 4 .

However, this study does replicate two genes [ILI $\beta$ (rs16944) and $F V$ (rs6025)] associated with the risk for IVH. IVH is a significant problem for very preterm VLBW infants. Although there is substantial research that has focused on understanding the etiology, mechanisms, and risk factors for IVH, little progress has been made in preventing this serious condition. It is important that continuing research focus on replicating previous findings and discovering new mechanisms and pathways for IVH. Identification of genetic risk factors can provide an opportunity to generate new therapeutic and preventative strategies in an era of personalized medicine.

Acknowledgments. We thank all the participating families in our study. We also thank the coordinating medical and research staff at the University of Iowa Children's Hospital in Iowa City, IA, including a special thanks to research coordinators Susan Berends and Laura Knosp. In addition, we thank the research technician involved in genotyping and sample management including Tamara Busch and student Diana Adebambo.

\section{REFERENCES}

1. Fanaroff AA, Stoll BJ, Wright LL, Carlo WA, Ehrenkranz RA, Stark AR, Bauer CR, Donovan EF, Korones SB, Laptook AR, Lemons JA, Oh W, Papile LA, Shankaran S, Stevenson DK, Tyson JE, Poole WK, NICHD Neonatal Research Network 2007 Trends in neonatal morbidity and mortality for very low birthweight infants. Am J Obstet Gynecol 196:147.e1-147.e8

2. McCrea HJ, Ment LR 2008 The diagnosis, management, and postnatal prevention of intraventricular hemorrhage in the preterm neonate. Clin Perinatol 35:777-792, vii

3. Pinto-Martin JA, Whitaker AH, Feldman JF, Van Rossem R, Paneth N 1999 Relation of cranial ultrasound abnormalities in low-birthweight infants to motor or cognitive performance at ages 2, 6, and 9 years. Dev Med Child Neurol 41:826-833

4. Vohr BR, Allan WC, Westerveld M, Schneider KC, Katz KH, Makuch RW, Ment LR 2003 School-age outcomes of very low birth weight infants in the indomethacin intraventricular hemorrhage prevention trial. Pediatrics 111:e340-e346

5. Heuchan AM, Evans N, Henderson Smart DJ, Simpson JM 2002 Perinatal risk factors for major intraventricular haemorrhage in the Australian and New Zealand Neonatal Network, 1995-97. Arch Dis Child Fetal Neonatal Ed 86:F86-F90, 2002

6. Alexander JM, Gilstrap LC, Cox SM, McIntire DM, Leveno KJ 1998 Clinical chorioamnionitis and the prognosis for very low birth weight infants. Obstet Gynecol 91:725-729

7. Linder N, Haskin O, Levit O, Klinger G, Prince T, Naor N, Turner P, Karmazyn B, Sirota L 2003 Risk factors for intraventricular hemorrhage in very low birth weight premature infants: a retrospective case-control study. Pediatrics 111:e590-e595

8. Spinillo A, Ometto A, Stronati M, Piazzi G, Iasci A, Rondini G 1995 Epidemiologic association between maternal smoking during pregnancy and intracranial hemorrhage in preterm infants. J Pediatr 127:472-478

9. Vergani P, Patane L, Doria P, Borroni C, Cappellini A, Pezzullo JC, Ghidini A 2000 Risk factors for neonatal intraventricular haemorrhage in spontaneous prematurity at 32 weeks gestation or less. Placenta 21:402-407

10. Baier RJ 2006 Genetics of perinatal brain injury in the preterm infant. Front Biosci 11:1371-1387

11. Göpel W, Härtel C, Ahrens P, König I, Kattner E, Kuhls E, Küster H, Möller J, Müller D, Roth B, Segerer H, Wieg C, Herting E 2006 Interleukin-6-174-genotype, sepsis and cerebral injury in very low birth weight infants. Genes Immun 7:65-68

12. Göpel W, Kattner E, Seidenberg J, Kohlmann T, Segerer H, Möller J; Genetic Factors in Neonatology Study Group 2002 The effect of the Val34Leu polymorphism 
in the factor XIII gene in infants with a birth weight below $1500 \mathrm{~g}$. J Pediatr 140:688-692

13. Havasi V, Komlosi K, Bene J, Melegh B 2006 Increased prevalence of glycoprotein IIb/IIIa Leu33Pro polymorphism in term infants with grade I intracranial haemorrhage. Neuropediatrics 37:67-71

14. Komlósi K, Havasi V, Bene J, Storcz J, Stankovics J, Mohay G, Weisenbach J, Kosztolányi G, Melegh B 2005 Increased prevalence of factor V Leiden mutation in premature but not in full-term infants with grade I intracranial haemorrhage. Biol Neonate 87:56-59

15. Petäjä J, Hiltunen L, Fellman V 2001 Increased risk of intraventricular hemorrhage in preterm infants with thrombophilia. Pediatr Res 49:643-646

16. Bhandari V, Bizzarro MJ, Shetty A, Zhong X, Page GP, Zhang H, Ment LR, Gruen JR Neonatal Genetics Study Group 2006 Familial and genetic susceptibility to major neonatal morbidities in preterm twins. Pediatrics 117:1901-1906

17. Adcock K, Hedberg C, Loggins J, Kruger TE, Baier RJ 2003 The TNF-alpha -308, MCP-1-2518 and TGF-beta1 +915 polymorphisms are not associated with the development of chronic lung disease in very low birth weight infants. Genes Immun 4:420-426

18. Harding DR, Dhamrait S, Whitelaw A, Humphries SE, Marlow N, Montgomery HE 2004 Does interleukin-6 genotype influence cerebral injury or developmental progress after preterm birth? Pediatrics 114:941-947

19. Dördelmann M, Kerk J, Dressler F, Brinkhaus MJ, Bartels DB, Dammann CE, Dörk T, Dammann O 2006 Interleukin-10 high producer allele and ultrasound-defined periventricular white matter abnormalities in preterm infants: a preliminary study. Neuropediatrics 37:130-136

20. Yanamandra K, Boggs P, Loggins J, Baier RJ 2005 Interleukin-10-1082 G/A polymorphism and risk of death or bronchopulmonary dysplasia in ventilated very low birth weight infants. Pediatr Pulmonol 39:426-432

21. Aronis S, Bouza H, Pergantou H, Kapsimalis Z, Platokouki H, Xanthou M 2002 Prothrombotic factors in neonates with cerebral thrombosis and intraventricular hemorrhage. Acta Paediatr Suppl 91:87-91

22. Göpel W, Gortner L, Kohlmann T, Schultz C, Möller J 2001 Low prevalence of large intraventricular haemorrhage in very low birthweight infants carrying the factor $\mathrm{V}$ Leiden or prothrombin G20210A mutation. Acta Paediatr 90:1021-1024

23. Derzbach L, Treszl A, Balogh A, Vasarhelyi B, Tulassay T, Rigo JJ 2005 Gender dependent association between perinatal morbidity and estrogen receptor-alpha Pvull polymorphism. J Perinat Med 33:461-462

24. Steffen KM, Cooper ME, Shi M, Caprau D, Simhan HN, Dagle JM, Marazita ML, Murray JC 2007 Maternal and fetal variation in genes of cholesterol metabolism is associated with preterm delivery. J Perinatol 27:672-680
25. Ehn NL, Cooper ME, Orr K, Shi M, Johnson MK, Caprau D, Dagle J, Steffen K, Johnson K, Marazita ML, Merrill D, Murray JC 2007 Evaluation of fetal and maternal genetic variation in the progesterone receptor gene for contributions to preterm birth. Pediatr Res 62:630-635

26. Rogers NL, Cole SA, Lan HC, Crossa A, Demerath EW 2007 New saliva DNA collection method compared to buccal cell collection techniques for epidemiological studies. Am J Hum Biol 19:319-326

27. Dupont WD, Plummer WD Jr 1990 Power and sample size calculations. A review and computer program. Control Clin Trials 11:116-128

28. Hwang IR, Kodama T, Kikuchi S, Sakai K, Peterson LE, Graham DY, Yamaoka Y 2002 Effect of interleukin 1 polymorphisms on gastric mucosal interleukin 1beta production in Helicobacter pylori infection. Gastroenterology 123:1793-1803

29. Cai Z, Pang Y, Lin S, Rhodes PG 2003 Differential roles of tumor necrosis factor-alpha and interleukin-1 beta in lipopolysaccharide-induced brain injury in the neonatal rat. Brain Res 975:37-47

30. Liu XH, Kwon D, Schielke GP, Yang GY, Silverstein FS, Barks JD 1999 Mice deficient in interleukin-1 converting enzyme are resistant to neonatal hypoxicischemic brain damage. J Cereb Blood Flow Metab 19:1099-1108

31. Kadhim H, Tabarki B, Verellen G, De Prez C, Rona AM, Sebire G 2001 Inflammatory cytokines in the pathogenesis of periventricular leukomalacia. Neurology 56:1278-1284

32. Yoon BH, Jun JK, Romero R, Park KH, Gomez R, Choi JH, Kim IO 1997 Amniotic fluid inflammatory cytokines (interleukin-6, interleukin-1beta, and tumor necrosis factor-alpha), neonatal brain white matter lesions, and cerebral palsy. Am J Obstet Gynecol 177:19-26

33. Kadhim H, Tabarki B, De Prez C, Sebire G 2003 Cytokine immunoreactivity in cortical and subcortical neurons in periventricular leukomalacia: are cytokines implicated in neuronal dysfunction in cerebral palsy? Acta Neuropathol 105:209216

34. Gilles FH, Price RA, Kevy SV, Berenberg W 1971 Fibrinolytic activity in the ganglionic eminence of the premature human brain. Biol Neonate 18:426-432

35. Hathaway W, Corrigan J 1991 Report of Scientific and Standardization Subcommittee on Neonatal Hemostasis. Normal coagulation data for fetuses and newborn infants. Thromb Haemost 65:323-325

36. Kalafatis M, Bertina RM, Rand MD, Mann KG 1995 Characterization of the molecular defect in factor VR506Q. J Biol Chem 270:4053-4057

37. Härtel C, König I, Köster S, Kattner E, Kuhls E, Küster H, Möller J, Müller D, Kribs A, Segerer H, Wieg C, Herting E, Göpel W 2006 Genetic polymorphisms of hemostasis genes and primary outcome of very low birth weight infants. Pediatrics 118:683-689 